03

\title{
Структура течения и колебания давления при взаимодействии сверхзвуковой недорасширенной струи газа с трубной полостью
}

\author{
() К.Н. Волков, В.Н. Емельянов, А.В. Ефремов, А.И. Цветков \\ Балтийский государственный технический университет „ВОЕНМЕХ“ им. Д.Ф. Устинова, \\ 190005 Санкт-Петербург, Россия \\ E-mail: dsci@mail.ru
}

Поступило в Редакцию 4 октября 2019 г.

В окончательной редакции 26 февраля 2020 г.

Принято к публикации 4 марта 2020 г.

\begin{abstract}
Сверхзвуковые струи широко используются в устройствах, построенных на явлении автоколебательного процесса, возникающего при взаимодействии газового потока с трубными полостями (газоструйные излучатели звука). Рассмотрены механизмы поддержания незатухающих пульсаций давления и определение поля течения в трубной полости при взаимодействии с ней сверхзвуковой недорасширенной струи. Обсуждена физическая картина течения в полости газоструйного излучателя, показано существование нечетных продольных мод, и предложены волновые диаграммы для описания течения в нечетных продольных модах. Волновые диаграммы построены на основе анализа сигналов пьезодатчиков, регистрирующих пульсации давления в трубной полости. Расчет параметров потока в трубной полости в продольных модах проведены на основе диаграммы скорость потока - скорость звука.
\end{abstract}

Ключевые слова: сверхзвуковая струя, газоструйный генератор, автоколебательный процесс, аэроакустический эффект.

DOI: $10.21883 / J T F .2020 .08 .49534 .328-19$

\section{Введение}

Возникновение пульсаций давления, связанных с неустойчивостью течения газа или жидкости, во многих случаях приводит к нарушению работы устройства или его фатальному разрушению. Примерами пульсаций, отрицательно действующих на различные процессы, являются пульсации давления в донных областях, камеpax сгорания, соплах, кавернах [1]. С другой стороны, существует ряд областей техники, в которых пульсации давления используются, например, для разрушения горных пород, интенсификации процессов химической технологии, сепарации мелкодисперсных частиц.

Одним из интересных технических приложений, связанных с пульсациями давления, является газоструйный излучатель звука. Эффект резонансного излучения звука короткой трубной полостью при натекании на нее сверхзвуковой недорасширенной струи был обнаружен Гартманом (I. Harmann) в 1916 г. В 1954 г. Шпренгером (M. Sprenger) был установлен эффект интенсивного выделения тепла на стенках длинной трубной полости вблизи ее дна (температура значительно превышала температуру торможения газовой струи). В явлении Гартмана-Шпренгера можно выделить три практически важных эффекта: эффект акустического излучения в окружающее пространство с преобладающим дискретным тоном; эффект пульсаций давления в трубной полости; эффект тепловыделения в трубной полости. Эффект акустического излучения используется в основном при построении различных схем мощных газоструйных излучателей звука в диапазоне частот свыше $1 \mathrm{kHz}$ и в ультразвуковом диапазоне. Эффект тепловыделения в трубной полости (нагрев донной области происходит за довольно короткий промежуток времени) находит применение при разработке конструкций воспламенителей горючих смесей.

Газоструйный излучатель представляет собой круглое сужающееся сопло, перед которым соосно с ним расположена цилиндрическая полость, своим открытым концом направленная навстречу газовой струе. Работа газоструйного излучателя звука основана на возникновении неустойчивого режима течения в сверхзвуковой недорасширенной струе при ее торможении полым резонатором. Для возбуждения в струе автоколебаний, сопровождаемых колебаниями скачков уплотнения и излучением акустических волн, срез резонатора находится в зоне неустойчивости (в области с положительным продольным градиентом статического давления в области первой бочки струи). Эффект акустического резонансного излучения проявляется в излучателях с короткой трубной полостью. В длинной трубной полости механизм пульсационного взаимодействия струи с полостью носит автоколебательный характер.

Кроме классического генератора Гартмана с цилиндрическим резонатором используются и другие конструкции, в частности, генераторы с резонаторами, сужающимися в направлении дна, а также дисковые генераторы. Привлекательность конусообразных резонаторов связана с усилением ударной волны по мере ее приближения к донной части. Для конусообразных резонаторов максимальное значение статического давления в несколько раз превышает давление тор- 
можения струи. В дисковых (радиальных) генераторах источником энергии для возбуждения и поддержания пульсаций в полости резонатора, образованного двумя дисками, служит щелевая кольцевая струя, направленная радиально к центральной оси симметрии резонатора. В модифицированных генераторах Гартмана наблюдаются более высокие амплитуды колебаний давления в резонаторе.

Результаты экспериментальных и численных исследований свободных сверхзвуковых струй, а также взаимодействия струй с преградами различной формы нашли отражение в большом числе публикаций [2-10]. При истечении из сопла и взаимодействии сверхзвуковой струи с резонирующей полостью возникает сложная система скачков уплотнения, и наблюдаются пространственные осцилляции давления, приводящие к возникновению обратной акустической связи. При малых скоростях истечения струи завихрения, возникающие в слое смешения, являются довольно слабыми, а ось струи остается прямолинейной. При некоторой пороговой скорости истечения струя теряет устойчивость, ее ось искривляется, a амплитуда колебаний давления увеличивается при удалении от среза сопла. Струя теряет устойчивость под влиянием случайных малых возмущений. Возмущения, возникающие в струе в окрестности кромки сопла, переносятся вниз по потоку и усиливаются, образуя локализованные вихревые структуры. Вихри, взаимодействуя с кромками резонатора, генерируют звуковые возмущения, которые усиливаются резонатором и воздействуют на струю (обратная связь). Экспериментально определены области различных режимов течений и получены эмпирические формулы для определения областей возникновения пульсаций. Кроме пульсаций на основной моде (частоте) собственных колебаний резонатора, в некоторых экспериментах обнаружены пульсации, соответствующие высоким модам (на более высоких частотах, близких к нечетным частотам основной моды).

Сверхзвуковая струя, втекающая в резонатор, в зависимости от внутренних размеров системы и параметров потока, реализует мощные автоколебания. В работах [11-13] изучается низкочастотный колебательный процесс взаимодействия воздушных струй с трубной полостью, когда частота процесса не превосходит акустической частоты трубы. Тепловые процессы при взаимодействии струи с полостью обсуждаются в работе [14]. Результаты исследований возникающих автоколебаний и акустических пульсаций, создаваемых взаимодействием струи с преградой, приводятся в работах [15-22]. При обтекании цилиндра, имеющего полость достаточно большой глубины, колебания головного скачка уплотнения происходят без существенного изменения его формы. Входная кромка цилиндра является местом генерации звуковых волн, которые, распространяясь вглубь полости, взаимодействуют с дном, отражаются, в результате чего образуются прямые и обратные бегущие звуковые волны, которые, складываясь, приводят к возникновению в полости стоячей звуковой волны, характеризующей резонансный процесс. Экспериментальные и численные результаты для различных полостей приводятся в работах [23-25]. В имеющихся публикациях как правило, изучается низкочастотный колебательный процесс взаимодействия воздушной струи с трубной полостью [11], когда частота процесса $f$ меныше или равняется акустической частоте трубы $f_{a}=a_{0} /(4 l)$, где $l$ - длина трубы, $a_{0}$ - скорость звука в окружающем пространстве.

Несмотря на то что аэроакустический эффект, возникающий при истекании сверхзвуковой струи в полость, был открыт более ста лет назад, и с тех пор проведено множество как экспериментальных, так и теоретических и численных исследований, посвященных изучению этого явления, все еще остаются нерешенные проблемы. Достаточно полный обзор таких проблем приводится в статьях [8-10].

В настоящей работе проводится экспериментальное исследование процесса взаимодействия сверхзвуковой струи с трубной и установившийся автоколебательный процесс в полости. Изучаются физические картины течения в трубной полости в первой и третьей продольных модах по результатам визуализации и регистрации картин с помощью теневого метода. Анализ картин течения выполняется с учетом сигналов датчиков давления, регистрирующих пульсации давления в трубной полости. По результатам анализа течения подтверждена справедливость модели течения в первой продольной моде и предлагаются (после анализа теневых картин) для описаний высокочастотных процессов с дискретными частотами волновые диаграммы и предельные циклы высших продольных мод.

\section{1. Схема измерений}

Рассмотрим сверхзвуковую струю воздуха, истекающую из сужающегося конического сопла и взаимодействующую с цилиндрической полостью, которая является соосной с соплом и обращена устьем к срезу сопла (рис. 1).

Экспериментальные исследования частотных характеристик сверхзвукового газоструйного генератора проводятся на струйном стенде при возбуждении колебательных процессов в тупиковой цилиндрической трубе с внутренним диаметром $d_{1}=25 \mathrm{~mm}$ и длиной $L_{1}=250 \mathrm{~mm}$ воздушными сверхзвуковыми струями, истекающими из конического сопла с углом полураствора

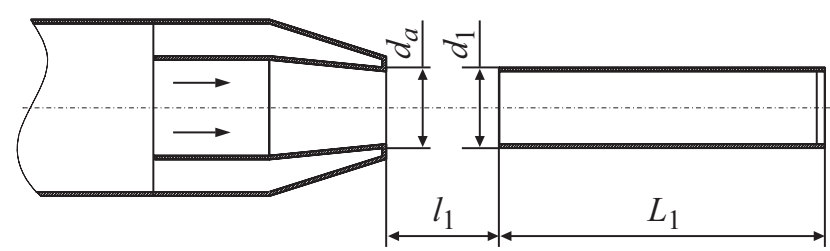

Рис. 1. Взаимодействие сверхзвуковой струи с цилиндрической полостью. 


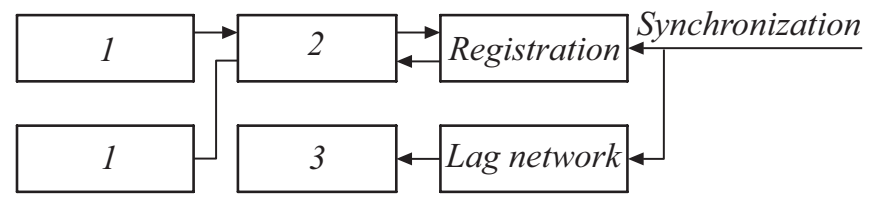

Рис. 2. Блок-схема измерительно-регистрирующего комплекса.

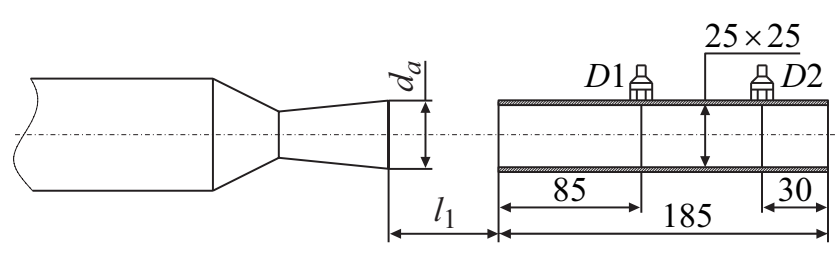

Рис. 3. Схема размещения датчиков давления.

$\theta_{a}=10^{\circ}$ и диаметром на выходе сопла $d_{a}=25 \mathrm{~mm}$. Параметры струй варьируются по числу Маха на срезе сопла $\mathrm{M}_{a}$ от 1.5 до 3.4 и по степени нерасчетности $n=p_{a} / p_{\infty}$ от 0.7 до 1.2, где $p_{a}$ - давление на срезе сопла, $p_{\infty}$ - давление в окружающем пространстве. Колебательные процессы исследуются при фиксированном расстоянии между соплом и трубной полостью. В качестве характерного линейного размера используется диаметр выходного сечения сопла. Для обозначения безразмерных параметров используется черта (например, $\left.\bar{l}_{1}=l_{1} / d_{a}\right)$.

Схема измерений показана на рис. 2. Пульсации давления в полости регистрируются по показаниям двух индуктивных датчиков давления ДДИ-20 1, работающих в комплекте со вторичным индуктивным высокочастотным преобразователем ИВП-2 2 и установленных в стенке трубной полости, а также по теневым фотографиям течения. Визуализация теневой картины течения в полости осуществляется с помощью теневого прибора ИАБ-451, а регистрация картины течения производится фотоаппаратом.

Инициирование искрового источника света ИИС 3 в данном методе производится с известной задержкой относительно начала развертки регистратора (электроннолучевого осциллографа), с помощью которого записываются сигналы датчиков давления. По осциллограммам определяются количественные данные по амплитуде, форме и временны́м параметрам процесса взаимодействия струи с трубной полостью, а также соответствие фотоснимков картине течения на временном интервале, равном периоду колебаний. Схема размещения в трубной полости датчиков давления (D1 и $D 2)$ приведена на рис. 3 (длины указаны в миллиметрах).

Электропривод на струйном стенде обеспечивает перемещение трубы на расстояние $l_{1}=1000 \mathrm{~mm}$ со скоростью $14 \mathrm{~mm} / \mathrm{s}$. Начальный зазор между соплом и трубой составляет $l_{1}=0.25 d_{a}$. С перемещением трубы синхронизирован механизм протяжки магнитного регистратора, на ленту которого записывались сигналы индуктивного датчика давления. Малая скорость перемещения трубы по отношению к скорости звука выбрана таким образом, чтобы для каждого дискретного значения $l_{1}$ сигналы датчика давления можно было рассматривать квазистационарными.

\section{2. Волновые диаграммы и предельные циклы колебаний}

При рассмотрении качественной картины течения в трубной полости используются волновые диаграммы. Волновая диаграмма течения в полости при натекании на нее сверхзвуковой струи построена в работе [11] для первой продольной моды на основе ряда упрощающих предположений. В настоящей работе построены волновые диаграммы и предельные циклы высших продольных мод.

\section{1. Основные допущения}

При построении волновой диаграммы принимается, что серии волн разрежения и волн сжатия изображаются на волновой диаграмме единичными волнами (волны считаются бесконечно тонкими поверхностями): волной разрежения (ВР), отраженной волной разрежения (ОВР), волной сжатия (ВС) или ударной волной $(У В)$, отраженной волной сжатия (ОВС) или отраженной ударной волной (ОУВ). При этом не учитывается взаимодействие этих волн с контактной поверхностью (КП), разделяющей собственный газ полости трубы от втекающего в полость газа струи.

Эффектами вязкости пренебрегается, что справедливо для относительно неглубоких полостей $\left(\bar{L}_{1}=4-5\right)$. УВ рассматриваются изэнтропическими, что справедливо при числе Маха струи вплоть до единицы. При $\mathrm{M}>1$ это допущение применимо для относительно неглубоких полостей, так как для образования УВ из волн сжатия необходима определенная дистанция. Волновые пучки прямых и отраженных волн сжатия и разрежения рассматриваются соответственно как единственные прямая УВ и ОУВ и ВР и ОВР.

Для оценки влияния тепловых эффектов, имеющих место в полости, принимается, что течение является изэнтропическим в каждом цикле колебаний, но температурный уровень собственного газа полости выше температуры окружающего воздуха (труба нагрета до конечной равновесной температуры до начала колебаний).

\section{2. Первая продольная мода}

Рассмотрим течение в трубной полости по волновой диаграмме, представленной на рис. 4 и соответствующей первой продольной моде. Расчет параметров пульсационного течения в трубной полости возможен при определении параметров течения в семи различных подобластях. 


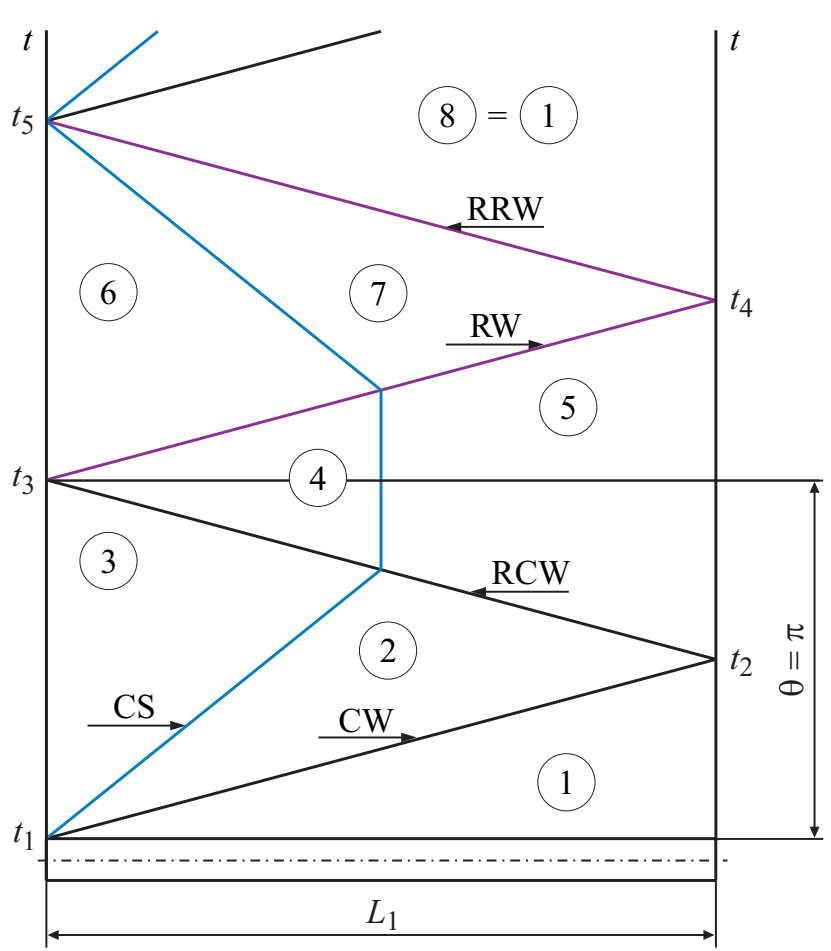

Рис. 4. Волновая диаграмма течения в полости при натекании на нее сверхзвуковой струи в первой продольной моде (RW волна разрежения, RRW - отраженная волна разрежения, $\mathrm{CW}$ - волна сжатия, RCW - отраженная волна сжатия, CS контактная поверхность).

Для расчета параметров потока в этих подобластях при рассмотрении взаимодействия с полостью дозвуковых струй имеется линейная теория, которая хорошо согласуется с экспериментальными результатами [11-13].

В момент времени $t_{1}$ цикла колебаний газа в трубной полости, соответствующий началу фазы сжатия (фазы втекания газа струи в трубную полость), давление в полости минимальное, и существуют условия для возникновения в устье трубной полости ВС, распространяющейся по собственному газу трубной полости к дну полости. С момента времени $t_{1}$ в трубную полость втекает газ струи. Собственный газ трубной полости за проходящей ВС вовлекается в движение в сторону дна полости. На волновой диаграмме показано перемещение КП, разделяющей собственный газ трубной полости от втекающего в нее газа струи. В момент времени $t_{2}$ ВС отражается от дна трубной полости. $\mathrm{OBC}$ направляется к устью полости. За ОВС скорость газа в трубной полости равна нулю. С приходом ОВС к устью полости в момент времени $t_{3}$ завершается фаза сжатия цикла колебаний. С момента времени $t_{3}$ начинается фаза разрежения цикла колебаний или фаза вытекания газа из трубной полости. От устья трубной полости в сторону ее дна распространяется серия волн разрежения, представленная на волновой диаграмме единичной ВР. В момент времени $t_{4}$ ВР взаимодействует с дном трубной полости, и к моменту времени $t_{5}$ подхода к устью полости единичной ОВР завершается опорожнение трубной полости до минимального давления. Течение в цикле колебаний переходит вновь к фазе сжатия. В устье трубной полости возникает новая ВC, направляющаяся к дну полости, и цикл колебаний газа в полости повторяется.

Для расчета параметров потока в различных подобластях (при рассмотрении взаимодействия с полостью дозвуковых струй с числом Маха струи на срезе сопла $\mathrm{M}_{i}=u_{i} / a_{\infty}<0.5$, индекс $i$ относится к срезу сопла) в работе [11] предложена линейная теория, которая хорошо согласуется с экспериментальными результатами. Давление в области 2 за ВС и давление в области 7 за ВР равняются давлению в окружающем пространстве, как и давления в областях 3 и $6\left(p_{2}=p_{7}=p_{\infty}, p_{3}=p_{2}\right.$, $\left.p_{6}=p_{7}\right)$. Средняя скорость всех волн на волновой диаграмме равняется скорости звука $a_{2}$ в области 2 волновой диаграммы. Число Маха потока в области 2 волновой диаграммы равняется числу Маха в струе $\left(\mathrm{M}_{2}=\mathrm{M}_{i}<1\right)$. Частота колебаний определяется из следующего соотношения:

$$
f_{1}=\frac{a_{2}}{4 L_{1}}\left[1+O\left(\mathrm{M}_{2}^{2}\right)\right] .
$$

Принимаются следующие соотношения

$$
\frac{p_{2}}{p_{1}}=\frac{p_{5}}{p_{2}}=\frac{p_{0}}{p_{\infty}}=1+\gamma \mathrm{M}_{2}+O\left(\mathrm{M}_{2}^{2}\right),
$$

где $p_{0}-$ полное давление в струе, $\gamma$ - отношение удельных теплоемкостей. Индекс $\infty$ относится к окружающей среде. Для проникающего в трубную полость газа струи в состоянии 3 справедливо уравнение постоянства теплосодержания

$$
a_{3}^{2}+\frac{\gamma-1}{2} u_{3}^{2}=a_{30}^{2},
$$

где $u_{3}=u_{2}-$ скорость газа струи. Индексом 0 отмечаются параметры торможения. Полученное уравнение в координатах $(a, u)$ представляет собой эллипс (эллипс энергии $E_{3}$ ). Для собственного газа полости в области 2 вводится свой эллипс энергии $E_{2}$

$$
a_{2 n}^{2}+\frac{\gamma-1}{2} u_{2 n}^{2}=a_{20}^{2}
$$

Индекс $n$ относится к предельному циклу установившихся колебаний.

В трубной полости течение нестационарное, и при исходных допущениях справедливы соотношения Римана

$$
\frac{2}{\gamma-1} a \pm u=\mathrm{const}, \quad \frac{a}{u}=\frac{\gamma-1}{2} .
$$

В координатах $A=a / a_{30}$ и $U=0.5(\gamma-1) u / a_{30}$ уравнения в подобластях и уравнения характеристик принимают вид

$$
A_{3}^{2}+\frac{2}{\gamma-1} U_{3}^{2}=1
$$




$$
\begin{gathered}
A_{3 n}^{2}+\frac{2}{\gamma-1} U_{3 n}^{2}=\alpha^{-1}, \\
A \pm U=\text { const. }
\end{gathered}
$$

Здесь $\alpha^{-1}=a_{20}^{2} / a_{30}^{2}=T_{20} / T_{30}$, где $T_{20}$ и $T_{30}$ - температуры торможения в соответствующих областях.

В предельном цикле колебаний $n$ для области 3 газа струи, проникающего в полость, имеем

$$
\frac{a_{3 n}}{a_{30}}=\left(\frac{p_{3 n}}{p_{30}}\right)^{(\gamma-1) /(2 \gamma)}
$$

где $a_{30}$ и $p_{30}$ - параметры торможения для газа струи.

При исходных допущениях для области 2 собственного газа трубной полости можно записать соотношение

$$
\frac{a_{2 n}}{a_{20}}=\left(\frac{p_{2 n}}{p_{20}}\right)^{(\gamma-1) /(2 \gamma)},
$$

где $a_{20}$ и $p_{20}$-параметры торможения для собственного газа трубной полости.

При сделанных допущениях $a_{20}$ имеет смысл скорости звука в собственном газе трубной полости при равновесной температуре стенок трубы. Скорости звука $a_{2 n}$ и $a_{3 n}$ относятся как

$$
\frac{a_{a n}^{2}}{a_{3 n}^{2}}=\frac{T_{20}\left(p_{2 n} / p_{20}\right)^{(\gamma-1) / \gamma}}{T_{30}\left(p_{3 n} / p_{30}\right)^{(\gamma-1) / \gamma}} .
$$

Используя соотношение на контактной поверхности $\left(p_{2 n}=p_{3 n}\right)$, получим

$$
\frac{A_{2 n}^{2}}{A_{3 n}^{2}}=\alpha^{-1} P^{(\gamma-1) / \gamma}
$$

где $P=p_{30} / p_{20}$ и $\alpha=1$ при отсутствии эффектов нагрева. С учетом условия на контактной поверхности $U_{2 n}=U_{3 n}$ эллипс энергии $E_{3}$ можно записать следующим образом

$$
\alpha P^{-(\gamma-1) / \gamma} A_{2 n}^{2}+\frac{2}{\gamma-1} U_{2 n}^{2}=1 .
$$

Рассмотрим предложенную схему колебаний газа в трубной полости по приведенной на рис. 5 диаграмме скорость потока - скорость звука. Данная диаграмма отражает связь между газодинамическими параметрами в различных областях волновой диаграммы.

$\mathrm{BC}$, возникающая в устье трубной полости в фазе сжатия цикла колебаний, движется к дну трубной полости. В координатах $(A, U) \mathrm{BC}$, рассматриваемая как изэнтропическая, исходит от точки $1^{\prime}(U=0, P=1$, $\left.A=\alpha^{-1 / 2}\right)$ с наклоном +1 . Пересечение этой волны с эллипсом энергии $E_{2}$ в точке $2^{\prime}$ определяет состояние течения 2 собственного газа трубной полости. Состояние течения газа струи, проникающего в полость, определяется точкой $3^{\prime}$ (здесь учитывается, что $u_{2}=u_{3}$ ).

Падающая на дно трубной полости ВС отражается от дна. ОВС для подобластей волновой диаграммы,

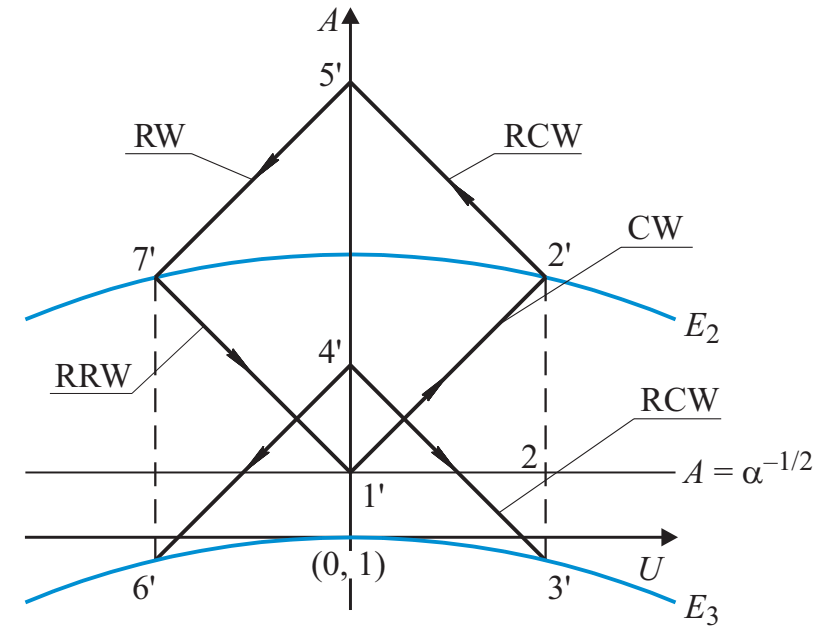

Рис. 5. Предельный цикл первой продольной моды.

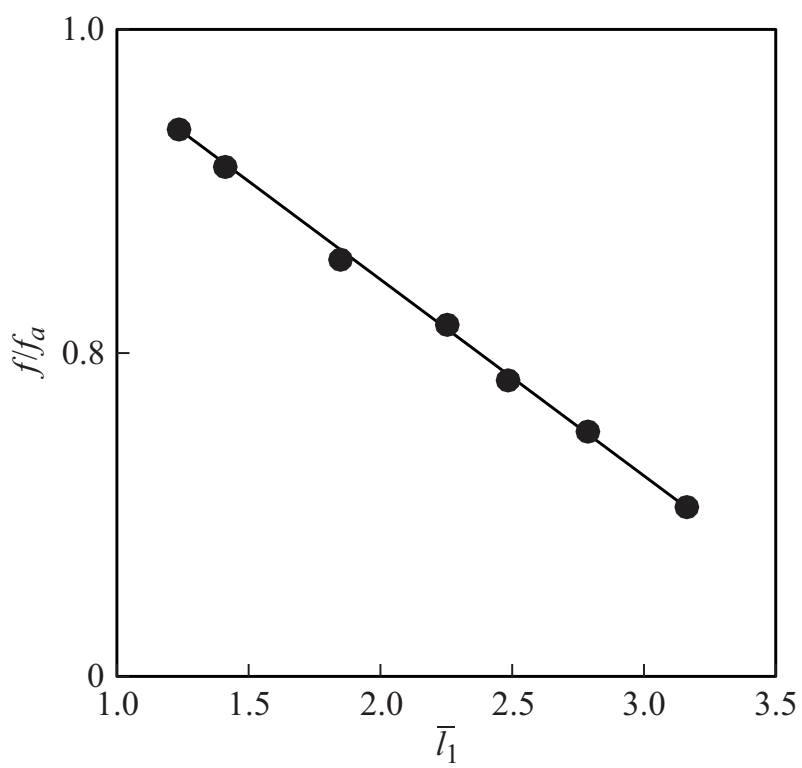

Рис. 6. Смещение основной частоты первой моды при $n=1$ и $\mathrm{M}_{a}=3.42$.

разделенных контактной поверхностью, представлена на рис. 5 соответствующими прямыми линиями с наклоном -1 . Одна из этих линий начинается от точки $2^{\prime}$, а другая - от точки $3^{\prime}$. Точки $4^{\prime}$ и $5^{\prime}(U=0)$ соответствуют состоянию течения 4 и 5 волновой диаграммы $\left(u_{4}=u_{5}=0\right)$.

С момента выхода из устья трубной полости ОВС начинается истечение газа из трубной полости. Внутрь полости распространяется ВР (прямая линия с наклоном +1 на диаграмме). Проникший в трубную полость в фазе втекания газ струи в начале фазы вытекания имеет полное давление по крайней мере равным полному давлению газа струи перед устьем трубной полости. В точке $4^{\prime}$ полное давление проникшего в трубную полость газа струи выше полного давления в струе $p_{0}$. В точке $6^{\prime}$ 
оно вновь становится равным $p_{0}$. Статическое давление и число Маха струи в точке $6^{\prime}$ равны соответствующим величинам давления и числа Маха струи в точке $3^{\prime}$. Состояние собственного газа трубной полости за ВР определяется точкой $7^{\prime}$, а ОВР приведет этот газ опять к точке $1^{\prime}$. Из рассмотренной картины течения следует, что цикл колебаний повторяется, а амплитуда колебаний давления в трубной полости остается постоянной с течением времени.

\section{3. Третья продольная мода}

В широкополосных автоколебательных системах с определенной фазо-частотной характеристикой нарастают амплитуды тех компонент, для которых выполняются условия баланса фаз в системе. Из анализа течения в трубной полости по волновой диаграмме первой продольной моды (рис. 4), а также с учетом того, что дискретные частоты колебательных процессов близки к нечетным гармоникам акустической частоты трубной полости, следует, что в газоструйном генераторе удовлетворяют условию баланса фаз компоненты или моды, у которых результирующий сдвиг фаз составляет $\theta=(2 m+1) \pi$, где $m=0,1,2, \ldots$ Такая автоколебательная система обладает дисперсией, когда существует разброс во времени прохождения возмущения от устья к дну трубной полости и обратно в зависимости от частоты колебательного процесса или частоты появления возмущений в устье трубной полости. Эти моды определяются как нечетные продольные моды в газоструйном генераторе.

Смещение основной частоты первой моды при удалении трубной полости от сопла показывает рис. 6 (точки соответствуют экспериментальным данным, а сплошная линия - их аппроксимации). Протяженность зоны первой моды по расстоянию составляет величину до двух диаметров сопла и более. За зоной первой моды наблюдается колебательный процесс сложного спектрального состава, частотные компоненты которого занимают полосу шириной от $f_{1}$ до $2 f_{1}$.

На основе экспериментальных данных течение в газоструйном сверхзвуковом генераторе в третьей продольной моде $(m=1)$ представляется в виде взаимодействия четырех единичных волн: УВ или ВС, ОУВ или ОВС, ВР, ОВР. Соответствующая волновая диаграмма модели течения для третьей продольной моды изображена на рис. 7. Допущения, принятые при построении данной модели, являются такими же, что и для первой продольной моды. Нумерация подобластей в полости трубы проставлена римскими цифрами от устья к дну полости. Границы между подобластями, на которых происходит взаимодействие единичных УВ (красные линии в online версии) и волн разрежения (зеленые линии в online версии), обозначены на рисунке как КП (синии линии в online версии).

В третьей продольной моде (рис. 7) по сравнению с первой продольной модой (рис. 4) проявляются отличи-

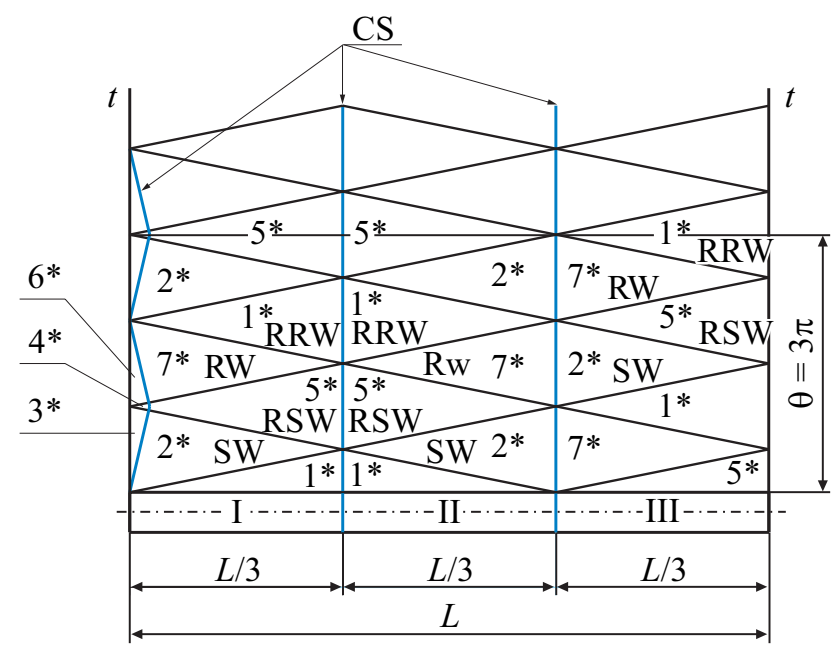

Рис. 7. Волновая диаграмма течения в полости при натекании на нее сверхзвуковой струи в третьей продольной моде $(\mathrm{SW}-$ ударная волна, RSW - отраженная ударная волна, RW волна разрежения, RRW - отраженная волна разрежения, $\mathrm{CS}$ - контактная поверхность).

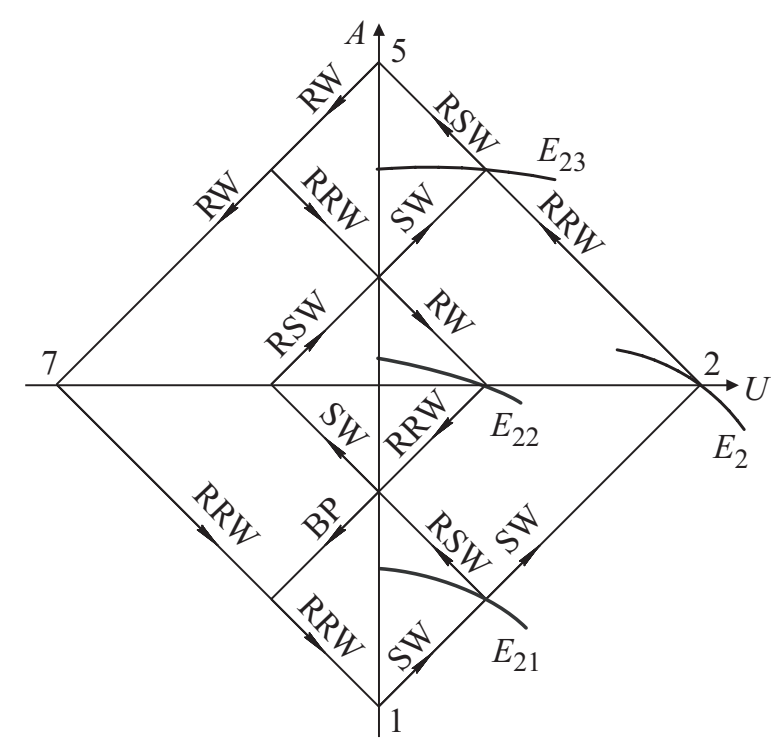

Рис. 8. Предельный цикл третьей продольной моды.

тельные особенности. В собственном газе полости существуют три подобласти, в каждой из которых протекает процесс с последовательным действием четырех волн (УВ-ОУВ-ВР-ОВР). В средней подобласти протекает процесс, обращенный по отношению к процессам в крайних подобластях. В третьей продольной моде значительно меньшее количество газа струи проникает в полость трубы. Частоты высших продольных мод обусловлены фазовым сдвигом в процессе возникновения возмущений (УВ или ВР) в устье трубной полости, распространением возмущений в полости и приходом отраженных от дна полости возмущений (ОУВ или ОВР), по отношению к процессу в первой продольной моде. 
Для каждой подобласти можно ввести свой эллипс энергии и показать подобие эллипсов. Предельный цикл третьей продольной моды приводится на рис. 8, который с учетом принятых допущений вписывается в предельный цикл 1-2-5-7-1 первой продольной моды. В средней подобласти третьей моды действует обращенный предельный цикл. В этой подобласти при прохождении по ней ударной волны собственный газ подобласти приобретает скорость в направлении, обратном выбранному положительному направлению координаты $U$.

\section{4. Высшие продольные моды}

В любой нечетной $(2 m+1)$ продольной моде в собственном газе полости существует $(2 m+1)$ подобластей, каждая из которых подвержена последовательному действию четырех волн (УВ-ОУВ-ВР-ОВР). С увеличением порядкового номера моды уменьшается амплитуда пульсаций давления в трубной полости. В моде $(2 m+1)$ уменьшается скорость втекания газа струи в трубную полость в $(2 m+1)$ раз по сравнению со скоростью втекания газа в первой продольной моде $(m=0)$. Средняя за цикл пульсаций температура собственного газа в первой моде приближенно определяется температурой собственного газа в состоянии 2, обусловленном прохождением по нему УВ. Максимальная температура собственного газа обусловлена прохождением по нему отраженной ударной волны (состояние 5). С увеличением порядкового номера моды средняя за цикл пульсаций температура в подобластях собственного газа вблизи дна полости растет, достигая в пределе максимальную температуру предельного цикла первой продольной моды $T_{5}$.

При построении предельного цикла высших продольных мод принимается, что течение изэнтропическое в предельном цикле колебаний в любой продольной моде, и в каждой подобласти собственного газа полости свой температурный уровень. При этом распределение температуры по подобластям такое, что $T_{\max _{i+1}}>T_{\max _{i}}=T_{\min _{i+1}}$, где $i-$ номер подобласти (нумерация следует по подобластям от устья к дну полости). Амплитуды пульсаций давления в подобластях равны между собой.

В качестве примера на рис. 9 представлен предельный цикл пятой продольной моды. С увеличением порядкового номера моды уменьшается амплитуда пульсаций давления в трубной полости.

Рассмотренную схему расчета параметров потока в трубной полости в первой продольной моде по ее предельному циклу можно распространить и на расчет параметров потока в полости в любой высшей продольной моде. При этом предполагается, что в моде $(2 m+1)$ скорость втекания газа струи в полость в $(2 m+1)$ раз меньше скорости втекания газа в первой продольной моде. В частности, для расчета амплитуд пульсаций давления в любой продольной моде можно

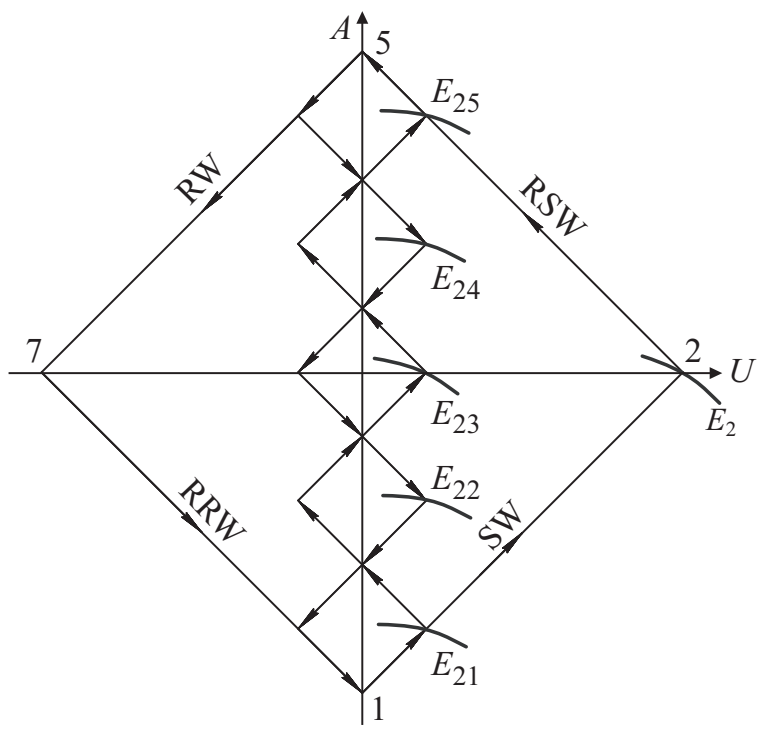

Рис. 9. Предельный цикл пятой продольной моды.

предложить следующие соотношения:

$$
\begin{aligned}
\left(\frac{p_{5}}{p_{2}}\right)_{(2 m+1)}= & {\left[1+\alpha^{1 / 2} \frac{\left(\frac{\gamma-1}{2}\right) \mathbf{M}_{i}}{(2 m+1)}\right.} \\
& \left.\times\left(1+\frac{\gamma-1}{2} \mathbf{M}_{i}^{2}\right)^{1 / 2}\right]^{2 \gamma /(\gamma-1)}, \\
\left(\frac{p_{1}}{p_{2}}\right)_{(2 m+1)}= & {\left[1-\alpha^{1 / 2} \frac{\left(\frac{\gamma-1}{2}\right) \mathbf{M}_{i}}{(2 m+1)}\right.} \\
& \left.\times\left(1+\frac{\gamma-1}{2} \mathbf{M}_{i}^{2}\right)^{1 / 2}\right]^{2 \gamma /(\gamma-1)} .
\end{aligned}
$$

Результаты сравнения результатов расчетов по предложенной модели с данными физического эксперимента дается в работе [26]. В частности, в этой работе проведено сравнение распределений амплитуд пульсаций давления в первой и третьей продольных модах в зависимости от расстояния между срезом сопла и трубной полостью и числа Маха на срезе сопла.

\section{3. Структура колебательного процесса}

При некоторых геометрических и режимных параметрах в трубной полости газоструйного генератора реализуются автоколебательные процессы с дискретной частотой, в несколько раз превышающей частоту первой продольной моды $f_{a}$. При взаимодействии стационарной сверхзвуковой струи с трубной полостью в определенных условиях происходит потеря устойчивости течения, и реализуется механизм, переводящий часть механической энергии струи в пульсации газа в полости трубы. Как правило, возникающие в полости пульсации 
давления имеют широкий спектр по частоте и сложный хаотический характер.

Исследование взаимодействия струи с неподвижной полостью показывает, что в полости при различном расстоянии между соплом и полостью наблюдаются колебательные процессы с выраженными дискретными частотами и процессы сложного спектрального состава. Что касается процессов с дискретной частотой, то частоты этих процессов не эквидистантны, но близки к нечетным гармоникам акустической частоты трубы $f_{a}$. Из анализа течения в первой продольной моде следует, что в устье трубной полости периодически появляются возмущения (УВ или ВР), которые проходят вглубь полости к ее дну, отражаются и через некоторое время (со сдвигом фаз $\theta=\pi$ ) возвращаются к устью полости (рис. 4).

Частотная характеристика газоструйного генератора дается на основе спектрального анализа сигналов индуктивного датчика давления, регистрирующего пульсации давления в полости трубы. Изучение течения в полости проводится по фотографиям течения, полученным в отдельных экспериментах, с привязкой фотографий к осциллограммам сигналов датчиков давления. При такой привязке можно расположить отдельные фотографии последовательно друг за другом на временном интервале, равном периоду колебаний $T$. По осциллограммам определяются количественные данные по амплитуде, форме и временны́м параметрам процесса взаимодействия струи с полостью, а также положение фотоснимков с картиной течения на временном интервале, равном периоду колебаний.

Приведем результаты физического эксперимента по изучению внутреннего течения в полости трубы в первой моде. Колебательные процессы возбуждаются в прозрачной трубной полости прямоугольного сечения $25 \times 25 \mathrm{~mm}$ и глубиной $L_{1}=185 \mathrm{~mm}$ сверхзвуковыми воздушным струями. Пульсации давления в полости регистрируются по показаниям двух датчиков давления (рис. 3), а также по теневым фотографиям течения. Осциллограммы сигналов датчиков, регистрирующих пульсации давления в первой продольной моде, приводятся на рис. 10.

Фотографии течения приводятся на рис. ?? для $n=1.2, \mathrm{M}_{a}=1.5, \bar{l}_{1}=1.0$ (при этом $f / f_{a}=0.92$, $\Delta p_{2} / p_{\infty}=1.1$ и $\left.\Delta p_{5} / p_{\infty}=5\right)$, характеризуя явление на промежутке времени за один период колебаний. Фотографии следует рассматривать в следующем порядке: в колонке они расположены сверху вниз, колонки идут слева направо. На фотографиях сопло находится слева, а трубная полость - справа. Темная полоса в устье трубы - грань оптического стекла. Фотографии достаточно трудно сопоставить определенному моменту времени; они служат для наглядности протекающих процессов в трубной полости.

В начале фазы сжатия в структуре сверхзвуковой струи, истекающей из сопла, наблюдается центральный скачок уплотнения, максимально удаленный от устья

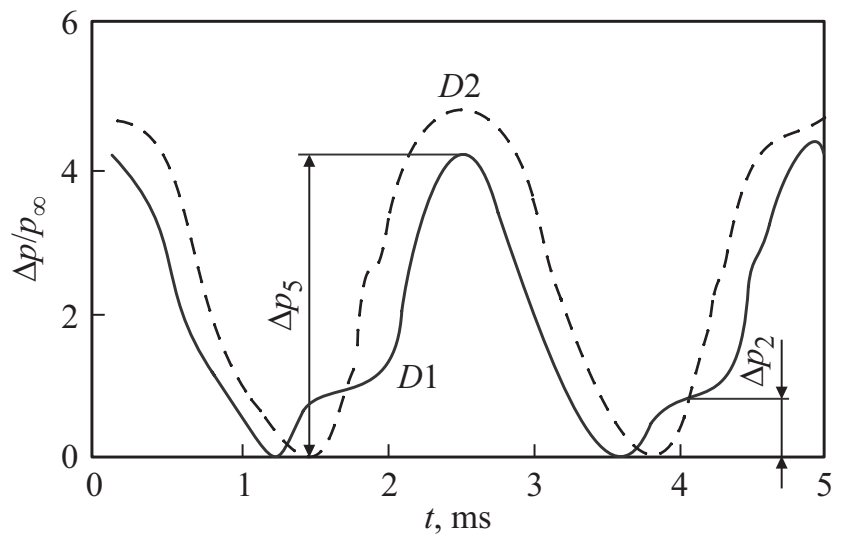

Рис. 10. Осциллограммы сигналов датчиков в первой продольной моде при $n=1.2, \mathrm{M}_{a}=1.5, \bar{l}_{1}=1$.

трубы (фото 1). В полости вблизи устья зарождается слабая УВ (или ВС на волновой диаграмме). С течением времени центральный скачок медленно перемещается к устью, а УВ движется к дну полости (фото 1-4). Происходит сжатие собственного газа полости и втекание газа струи в трубную полость.

При втекании в полость газа струи в устье образуется тороидальный вихрь (отчетливо наблюдается на других сериях фотографий). К моменту времени $t_{6}$ центральный скачок занимает положение, близкое к положению диска Маха в свободной сверхзвуковой струе. При этом дозвуковой поток за скачком в момент времени $t_{2}$ становится сверхзвуковым (как и в свободной струе). Газ струи частично проникает в полость по центру поперечного сечения трубы, а также растекается вдоль торцевой поверхности трубы в направлении от оси трубы в веерной струе, охватывающей устье трубы по периметру. Торможение периферийного потока газа перед торцом трубы происходит на скачке уплотнения. Некоторое время перепад давления на этом скачке, с одной стороны, тормозит газ струи, прошедший центральный скачок уплотнения, а с другой стороны, способствует затеканию в полость газа периферийного потока, что объясняет появление тороидального вихря в устье трубы. В момент времени $t_{6}$ весь газ струи попадает в полость, так как кольцевой скачок уплотнения в периферийном потоке газа к этому моменту времени пропадает. При этом за центральным скачком скорость газа в направлении к устью трубы быстро возрастает, а центральный скачок резко перемещается к устью. Струя поглощается трубой с распространением волн сжатия навстречу отраженной от дна полости ударной волне (фото 5-7).

От дна ОУВ на своем пути взаимодействует не только с КП, разделяющей собственный газ полости от проникающего в полость газа струи, но и с возникшими при поглощении струи полостью волнами сжатия. На последнем участке фронт ОУВ перестает быть гладким (фото 6-8). С приходом отраженной волны к устью завершается фаза сжатия цикла. Газ 


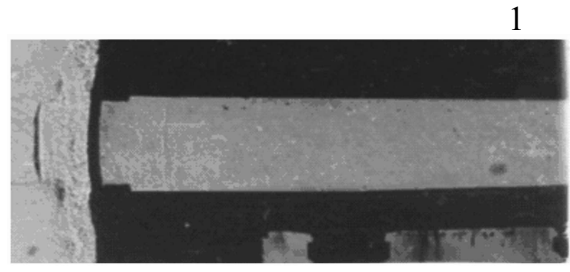

2

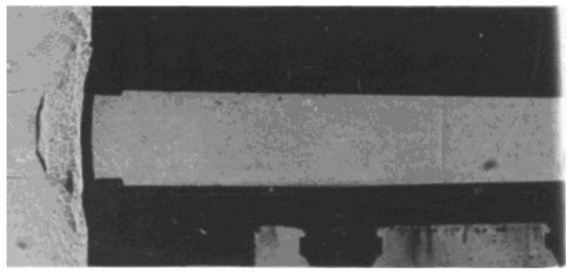

3

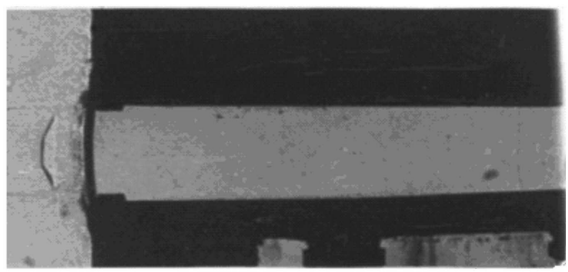

4

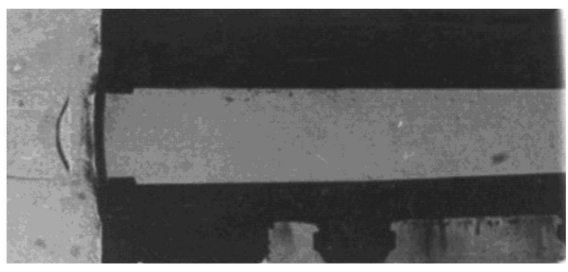

5

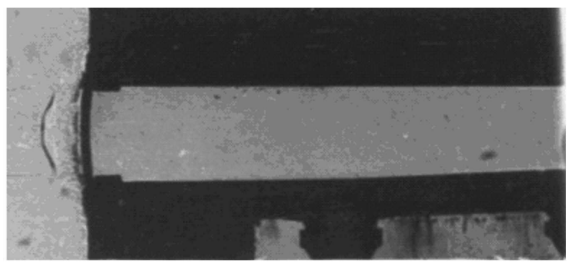

6

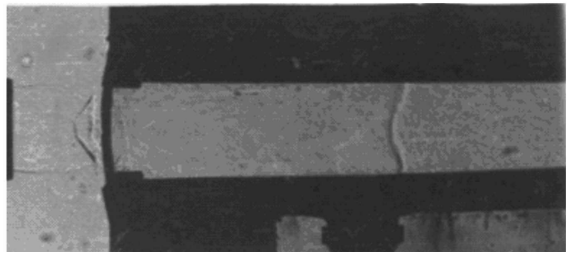

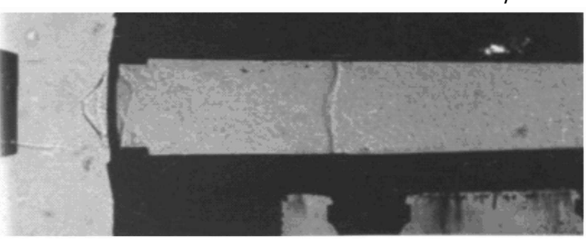

8

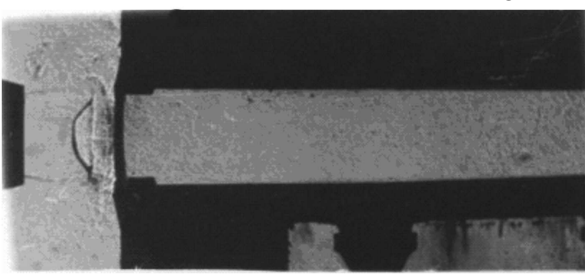

9

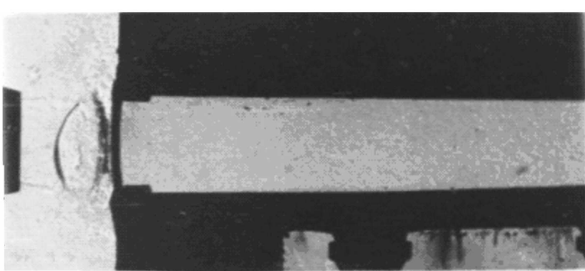

10

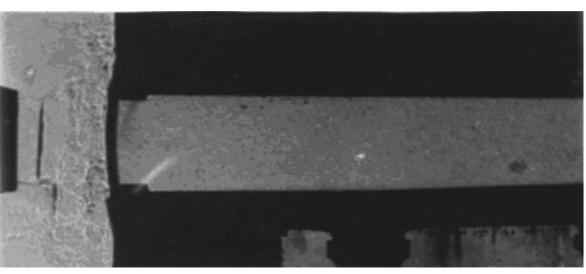

11

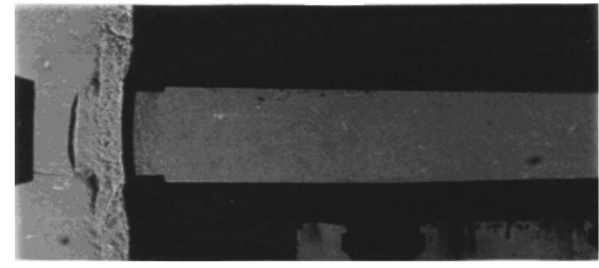

12

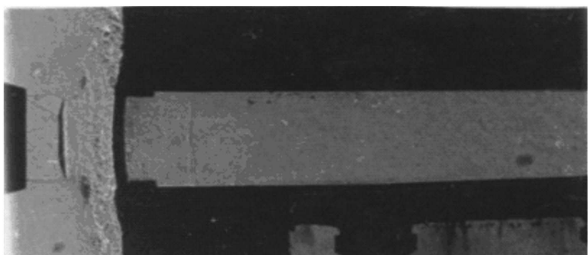

Рис. 11. Теневые фотографии процесса в первой продольной моде при $n=1.2, \mathrm{M}_{a}=1.5, \bar{l}_{1}=1.0$.

начинает вытекать из полости трубы. С этого момента внутрь полости проникает серия ВР. В области между соплом и трубой наблюдается столкновение двух встречных течений: сверхзвуковой струи и струи вытекающего из трубы газа. Истекающий газ разгоняется, и между устьем и центральным скачком образуется волна торможения (фото 8-9). С течением времени волна торможения и центральный скачок перемещаются к соплу и останавливаются (фото 8-10). Затем по мере опорожнения полости трубы вновь возникают условия для возобновления фазы сжатия цикла колебаний. 
1

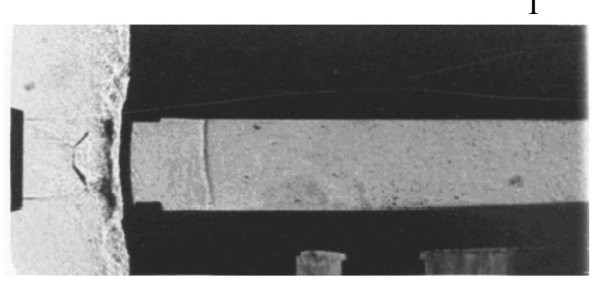

2

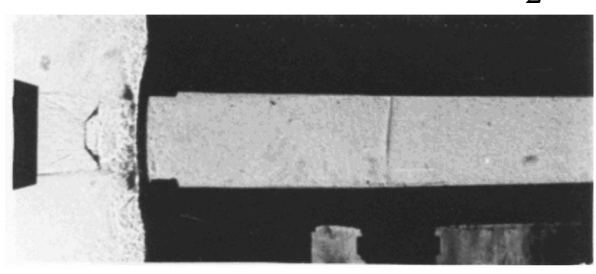

3

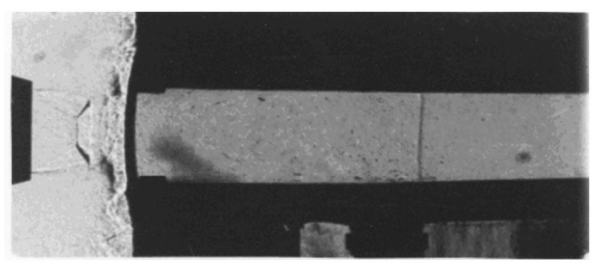

4

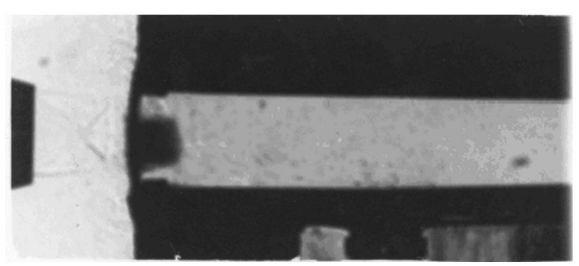

5

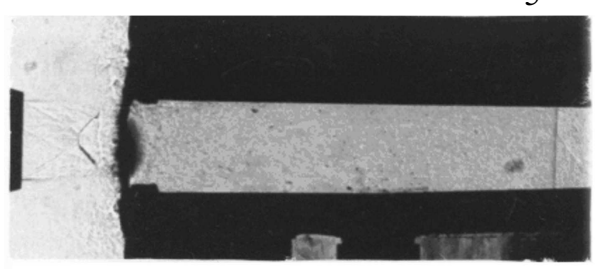

6

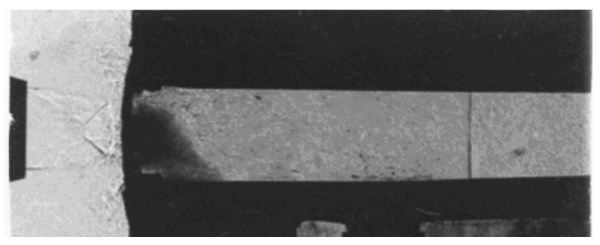

7

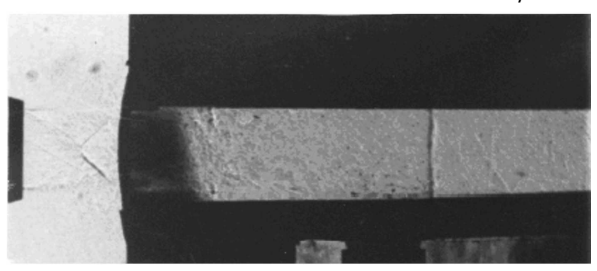

8

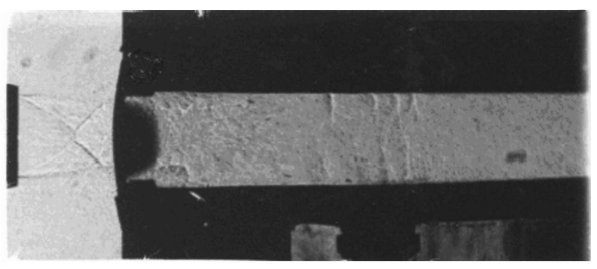

9

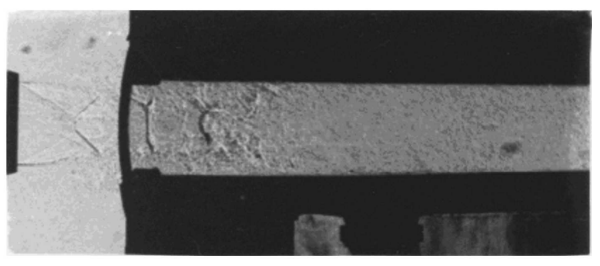

10

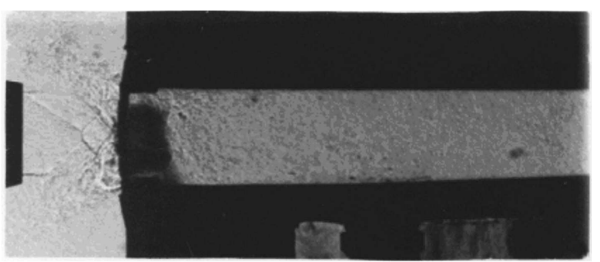

11

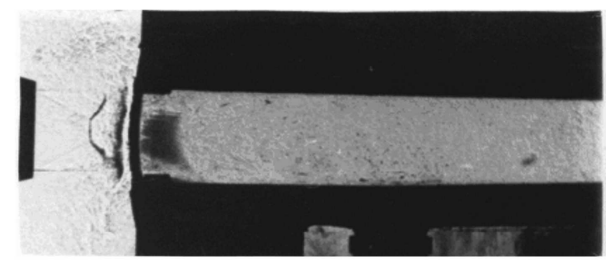

12

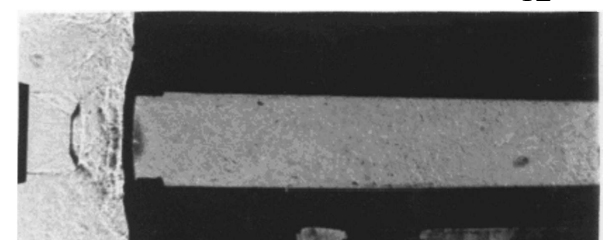

Рис. 12. Теневые фотографии процесса в первой продольной моде при $n=0.7, \mathrm{M}_{a}=2.0, \bar{l}_{1}=1.2$.

Изложенная на основе теневых фотографий картина течения подтверждается показаниями датчиков давления, сигналы которых приводятся на рис. 10. В фазе сжатия цикла колебаний датчик $D 1$ регистрирует прохождение УВ к дну полости $\left(\Delta p_{2}=p_{2}-p_{\min }\right)$ и приход ОУВ $\left(\Delta p_{5}=p_{5}-p_{\min }\right)$. Датчик $D 2$, установленный вблизи дна полости, при временно́й развертке осциллограммы практически не выделяет прохождение падающей УВ и показывает давление за ОУВ. В фазе вытекания датчики регистрируют падение давления в волнах разрежения ВР и ОВР.

Для других параметров задачи фотографии течения приводятся на рис. 12 для $n=0.7, \mathrm{M}_{a}=2.0, \bar{l}_{1}=1.2$ (при этом $f / f_{a}=0.89, \Delta p_{2} / p_{\infty}=1.1$ и $\Delta p_{5} / p_{\infty}=4.5$ ) 


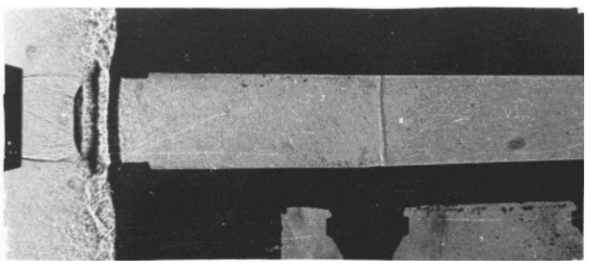

2

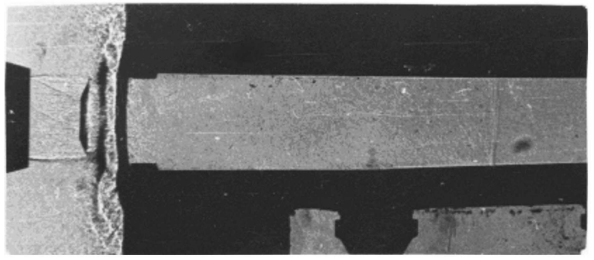

3

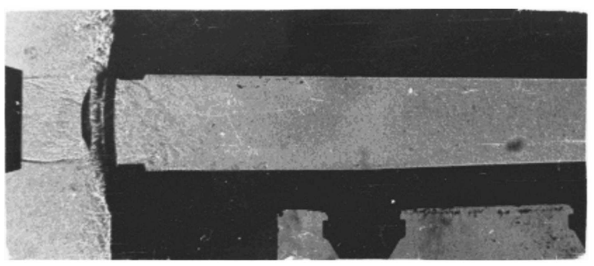

4

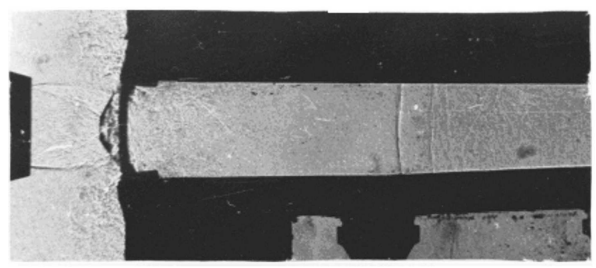

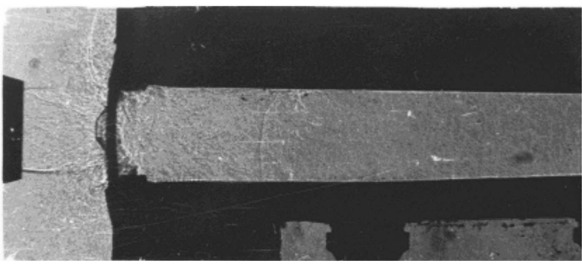

6
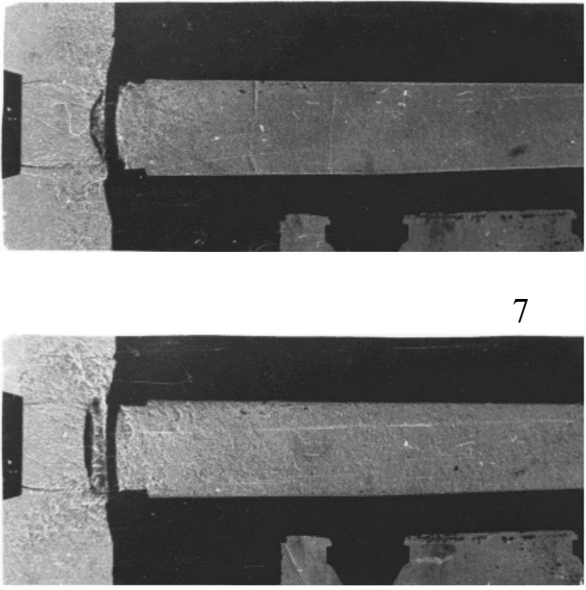

8

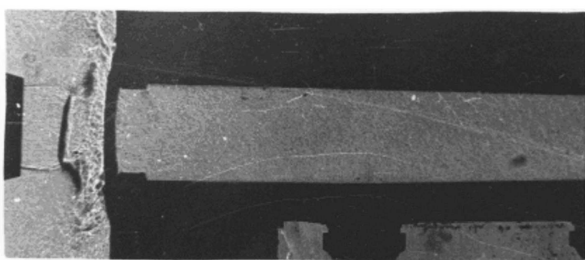

Рис. 13. Теневые фотографии процесса в первой продольной моде при $n=1.0, \mathrm{M}_{a}=2.0, \bar{l}_{1}=1.12$.

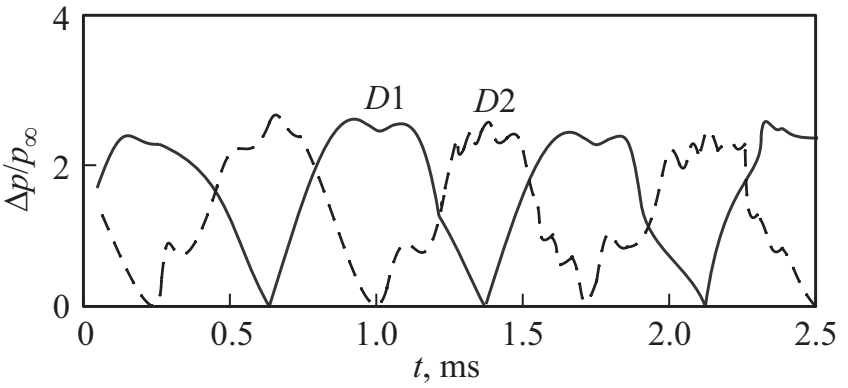

Рис. 14. Осциллограммы сигналов датчиков в третьей продольной моде при $n=1.2, \mathrm{M}_{a}=1.5, \bar{l}_{1}=0.8$.

и рис. 13 для $n=1.0, \mathrm{M}_{a}=2.0, \bar{l}_{1}=1.12$ (при этом $f / f_{a}=0.93, \Delta p_{2} / p_{\infty}=1.3$ и $\left.\Delta p_{5} / p_{\infty}=6\right)$.

В сверхзвуковом газоструйном генераторе существуют нечетные продольные моды с результирующим сдвигом фаз $\theta=(2 m+1) \pi$ и отношением частот $f_{i} / f_{a}$, близким к $(2 m+1)$, где $m=0,1,2, \ldots$ Расстояние между соплом и трубной полостью при неизменных параметрах струи определяет процесс генерации той или иной моды. Зоны высших мод локализованы в узком диапазоне расстояний между соплом и полостью.

Рассмотрим процесс колебаний в третьей продольной моде, который наблюдается при расстоянии $\bar{l}_{1}=0.8$ (при $\left.n=1.2, \mathrm{M}_{a}=1.5\right)$. Осциллограммы сигналов датчиков давления $D 1$ и $D 2$ для этого процесса приведены на рис. 14. Оба датчика регистрируют фазу нарастания давления и фазу разрежения, причем пульсации давления в точках установки датчиков происходят практически в противофазе.

Фотографии течения, характеризующие цикл рассматриваемого колебательного процесса, приведены на рис. 15. Фотографии показывают, что в трубной полости наблюдаются две движущиеся в противофазе УВ. Фото 1-4 иллюстрируют процесс зарождения волн сжатия вблизи устья и их движение навстречу отраженной от дна трубной полости УВ. На некотором расстоянии от устья завершается процесс формирования волн сжатия в УВ (фото 4,5). Две встречные УВ взаимодействуют, одна из них направляется к устью, а другая к дну поло- 
1

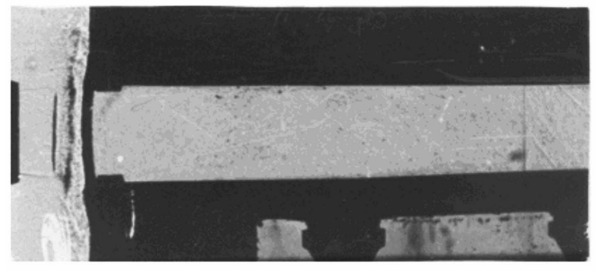

2

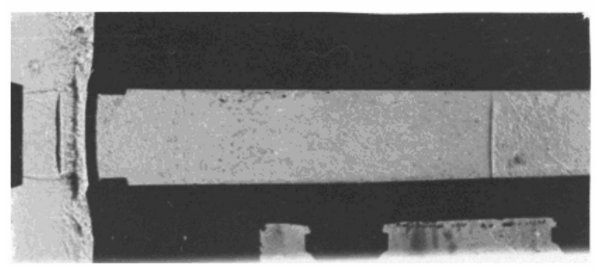

3

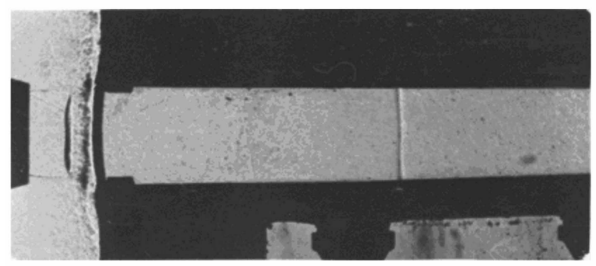

4

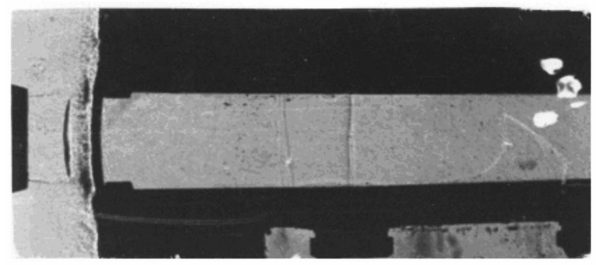

5

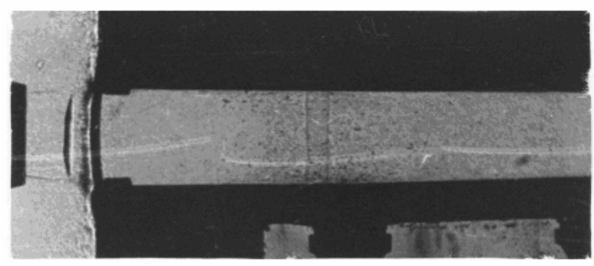

6

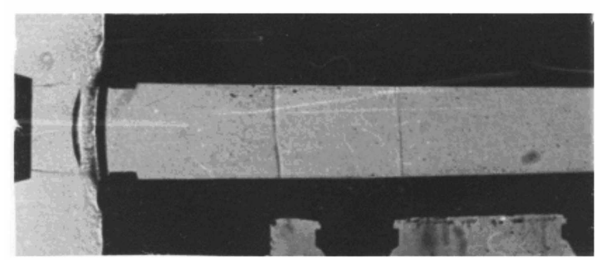

7

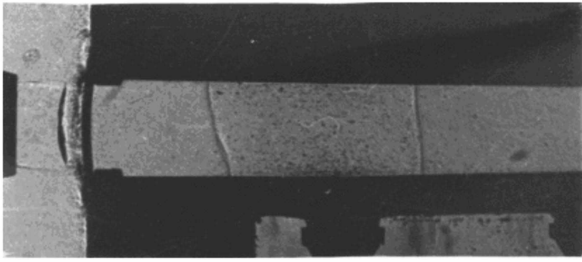

8

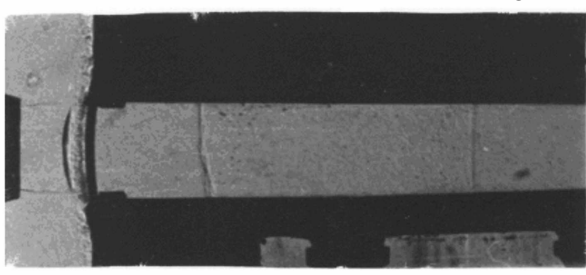

9

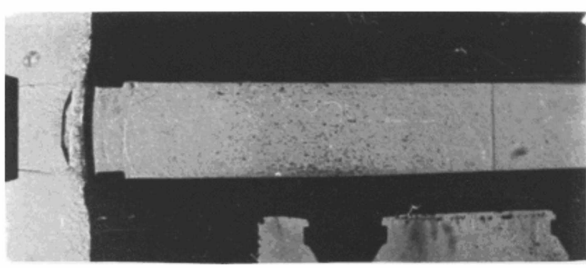

10

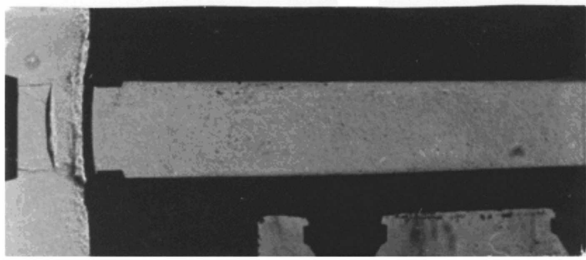

11

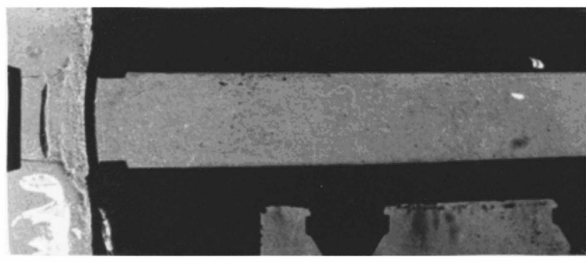

12

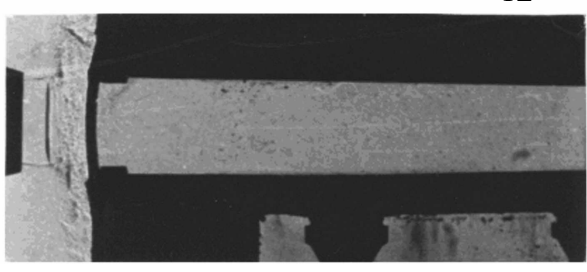

Рис. 15. Теневые фотографии процесса в третьей продольной моде при $n=1.2, \mathrm{M}_{a}=1.5, \bar{l}_{1}=0.8$.

сти (фото 6-9). В узкой области между расходящимися УВ наблюдается турбулизация потока, что, возможно, является доказательством появления здесь контактной поверхности. Направляющаяся к устью ударная волна встречается вблизи устья с неоднородным потоком затекающего в трубу газа струи, вследствие чего ее фронт искривляется. Во внешнем поле течения в структуре струи наблюдается центральный скачок уплотнения, который колеблется с частотой процесса ( $3 f_{a}$ от сопла к устью и обратно). При малых расстояниях между устьем и соплом скачок проникает внутрь сопла. Газ струи в основном растекается в веерной струе, охватывающей 
устье трубной полости по периметру, но некоторая часть газа струи участвует в пульсирующем процессе втекания в трубу и вытекания из нее.

\section{Заключение}

При взаимодействии сверхзвуковой струи с трубной полостью существуют колебательные процессы, которые можно определить как нечетные продольные моды со своей основной частотой и гармониками, а также колебательные процессы сложного спектрального состава с амплитудами, сравнимыми с амплитудой процесса в первой продольной моде. Автоколебательный процесс, реализующийся при взаимодействии сверхзвуковой струи с трубной полостью в первой и высших модах колебаний, согласуется с имеющимися теоретическими моделями. Определены области положения среза резонатора относительно набегающей сверхзвуковой нерасчетной струи, при которых возникают сильные пульсации статического давления.

Характер течения (мода, частота и амплитуда пульсаций) определяется прохождением возмущений по внутреннему, а также по внешнему каналу связи. Внутренним каналом является путь движения волн сжатия и разрежения внутри резонатора, а внешним каналом путь по которому вышедшие из резонатора волны по периферийной части струи движутся вверх по струе до среза сопла, и, возмущая поток, возвращаются к резонатору. Проведенные исследования позволили изучить физические картины внешнего (между соплом и полостью) и внутреннего (в полости трубы) полей течения в третьей продольной моде и предложить волновые диаграммы высших нечетных продольных мод в сверхзвуковом газоструйном генераторе. При высокочастотном процессе (высшие продольные моды) взаимодействия сверхзвуковых струй с трубными полостями обнаружены более высокие, чем при низкочастотном процессе (первая продольная мода) взаимодействия, температуры вблизи дна полости. Частоты высших продольных мод в 3-7 раз превышали частоту первой моды.

\section{Конфликт интересов}

Авторы заявляют, что у них нет конфликта интересов.
[5] Волков К.Н., Емельянов В.Н., Зазимко В.А. Турбулентные струи: статические модели и моделирование крупных вихрей. М.: Физматлит, 2014. 360 с.

[6] Chin C., Li M., Harkin C., Rochwerger T., Chan L., Ooi A. // J. Fluids Eng. 2013. Vol. 135. N 3. 031202 (12 p.).

[7] Zapryagaev V., Kiselev N., Gubanov D. // Aerospace. 2018. Vol. 5. P. N 60 (18 p.).

[8] Бочарова О.В., Лебедев М.Г. // Хим. физ. 2011. Т. 30. № 7. C. $40-47$.

[9] Бочарова О.В., Лебедев М.Г. // Инженерный журнал: наука и инновации. 2018. № 9. С. 1-25.

[10] Afzali B., Karimi H. // Proceedings of the Institution of Mechanical Eng. Part G: J. Aerospace Eng. 2016. Vol. 231. N 14. P. 2706-2722.

[11] Brocher E., Maresca C., Bournay M.-H. // J. Fluid Mechan. 1970. Vol. 43. P. 369-384.

[12] Brocher E., Duport E. // AIAA J. 1988. Vol. 26. N 5. P. 548 552.

[13] Braud C., Dyment A. // Phys. Fluids. 2012. Vol. 24. N 4. P. 047102.

[14] Sarohia V., Back L.H. // J. Fluid Mechan. 1979. Vol. 94. P. 649-672.

[15] Дулов В.Г., Кузьмина В.Е., Угрюмов Е.А. Автоколебательные режимы взаимодействия струи с преградами. Гидроаэромеханика. СПб: Изд-во СПбГУ, 1999. С. 74-94.

[16] Горшков Г.Ф., Усков В.Н. // Прикладная математика и техническая физика. 1999. Т. 40. № 4. С. 143-149.

[17] Адрианов А.Л., Безруков А.А., Гапоненко Ю.А. // Прикладная математика и техническая физика. 2000. Т. 41. № 4. C. 106-111.

[18] Глазнев В.Н., Коробейников Ю.Г. // Прикладная математика и техническая физика. 2001. Т. 42. № 4. С. 62-67.

[19] Dauptain A., Cuenot B., Gicquel L.Y.M. // AIAA J. 2010. Vol. 48. N 10. P. 2325-2338.

[20] Davis T.B., Kumar R. // Shock Waves. 2015. Vol. 25. N 5. P. 507-520.

[21] Hildebrand N., Nichols J.W. // AIAA Paper. 2015. N 2015-2212.

[22] Mason-Smith N., Edgington-Mitchell D., Buchmann N.A., Honnery D.R., Soria J. // Shock Waves. 2015. Vol. 25. N 6. P. 611-622.

[23] Hamed A., Das K., Basu D. // AIAA Paper. 2002. N 2002-1118.

[24] Handa T., Miyachi H., Kakuno H., Ozaki T., Maruyama S. // AIAA J. 2015. Vol. 53. N 2. P. 420-425.

[25] Chung K.M., Lee K.H., Chang K.C. // J. Aircraft. 2016. Vol. 53. N 5. P. 1565-1567.

[26] Волков К.Н., Емельянов В.Н., Ефремов А.В., Цветков А.И. // ЖТФ. 2020. Т. 90. № 5. С. 733-739.

\section{Список литературы}

[1] Emelyanov V.N., Teterina I.V., Volkov K.N., Garkushev A.U. // Acta Astronautica. 2017. Vol. 135. P. 161-171.

[2] Дулов В.Г., Лукьянов Г.А. Газодинамика процессов истечения. Новосибирск: Наука, 1984. 236 с.

[3] Raman G., Srinivasan K. // Progr. in Aerospace Sci. 2009. Vol. 45. N 4. P. 97-123.

[4] Бойко В.М., Достовалов А.В., Запрягаев В.И., Кавун И.Н., Киселев Н.П., Пивоваров А.А. // Ученые записки ЦАГИ. 2010. T. 41. № 2. C. 44-57. 